\title{
Karakteristik Ekosistem Mangrove di Kawasan Pesisir Kepulauan Natuna
}

\author{
Characteristic of Mangrove Ecosystem in Natuna Island Coastal Area
}

\author{
Muarif
}

\begin{abstract}
The aims of study to determine the quality of mangrove ecosystems in the Coastal of Natuna Islands by analysis species distribution and mangrove density. Typology of mangrove ecosystem in this coastal zone was riverine mangrove. The quality of mangrove ecosystem was catagorized good. Mangrove species in this area including Sonneratia alba, Rhizophora mucronata, Bruguiera gymnorhiza, Rhizophora stylosa,Ceriops tagal, Rhizophora apiculata, Xylocarpus granatum, Hibiscus, Casuariana, and Pandanus. The density of mangroves in the coastal area is categorized as fulled to very fulled with density range of 1,000-2,933 idv / ha. Bunguran Barat District has the widest mangrove area and the highest density of trees $(1,833 \mathrm{idv} /$ Ha). Mangrove ecosystem in the Natuna Islands was dominated by Rhizophora, with dominant species such as Rhizophora mucronata, Rhizophora stylosa, and Rhizophora apiculata.
\end{abstract}

Keywords: ecosystem, density, mangrove

\begin{abstract}
ABSTRAK
Penelitian ini bertujuan untuk mengetahui kondisi kualitas ekosistem mangrove di Pesisir Kepulauan Natuna melalui analisis sebaran jenis dan kerapatan mangrove. Ekosistem mangrove di Kawasan Pesisir ini memiliki tipologi Riverine Mangrove. Kondisi ekosistem mangrove baik. Jenis mangrove yang tumbuh meliputi Sonneratia alba, Rhizophora mucronata, Bruguiera gymnorhiza, Rhizophora stylosa,Ceriops tagal, Rhizophora apiculata.Xylocarpus granatum, Hibiscus, Casuariana, dan Pandanus. Kerapatan mangrove di pesisir kawasan ini tergolong padat sampai sangat padat dengan kisaran nilai kerapatan antara 1.000-2.933 idv/Ha. Kecamatan Bunguran Barat memiliki areal mangrove terluas dengan rataan kerapatan pohon yang tertinggi $(1.833 \mathrm{idv} / \mathrm{Ha})$. Ekosistem mangrove di Kepulauan Natuna rata-rata didominansi oleh Genus Rhizophora dengan jenis yang mendominasi antara lain Rhizophora mucronata, Rhizophora stylosa, dan Rhizophora apiculata.
\end{abstract}

Kata kunci: ekosistem, kerapatan, mangrove

Muarif. 2017. Karakteristik Ekosistem Mangrove di Kawasan Pesisir Kepulauan Natuan. Jurnal Mina Sains 3(2): 44-49.

\section{PENDAHULUAN}

Kabupaten Kepulauan Natuna adalah kabupaten yang memiliki posisi terdepan dari wilayah Negara Republik Indonesia. Kabupaten ini menghadap perbatasan Indonesia dengan negara tetangga, antara lain Malaysia, Vietnam, dan Filipina (BPS Kabupaten Natuna 2014). Kabupaten ini memiliki posisi yang strategis baik dari segi bisnis maupun pertahanan dan keamanan.
Secara administrasi Kabupaten Natuna berada di wilayah Provinsi Kepulauan Riau (KEPRI), sedangkan secara geografis terletak pada titik-titik koordinat antara $1^{0} 16^{\prime}-7^{0} 19^{\prime}$ Lintang Utara (LU) dan $105^{\circ} 00^{\prime}-110^{\circ} 00^{\prime}$ Bujur Timur (BT). Luas wilayah kabupaten ini adalah 264.198,37 $\mathrm{Km}^{2}$ terdiri dari daratan seluas $2.001,30 \mathrm{Km}^{2}$ dan wilayah laut seluas 262.197,07 $\mathrm{Km}^{2}$ (BPS Kabupaten Natuna 2014).

Karakteristik wilayah yang sebagian besar berupa lautan $(99,24 \%)$ menjadikan 
pembangunan kelautan dan perikanan menjadi sector utama yang perlu dikembangkan untuk memanfaatkan peluang bisnis strategis di kabupaten ini. Berbagai sumberdaya kelautan dan perikanan sangat potensial dikembangkan dan dikelola dengan baik sehingga pemanfaatannya akan memberikan nilai ekonomi yang tinggi dan berkelanjutan.

Pengembangan wilayah berbasis sumberdaya kelautan dan perikanan yang berkelanjutan membutuhkan dukungan kondisi ekosistem pesisir yang baik. Ekosistem mangrove potensial mendukung sumberdaya kelautan dan perikanan yang produktif dan lestari. Ekosistem mangrove dikenal memegang peran fungsi ekonomi dan fungsi ekologi (Muarif et al. 2016), serta jasa lingkungan (Muarif, 2016b) yang memberikan sumbangan penting dalam pembangunan di kawasan pesisir dan laut.

Ekosistem mangrove ini perlu dijaga kualitas dan kelestariannya. Penurunan kualitas ekosistem mangrove akan menyebabkan menurunnya produktivitas sumberdaya kelautan termasuk produktivitas perikanan di kawasan lain yang memiliki konektivitas ekologi dengan ekosistem mangrove tersebut (Muarif 2016a). Wilayah konektivitas yang dimaksud meliputi kawasan daratan dan lautan (MacDonald 2008), sehingga akan berdampak menurunkan kesejahteraan masyarakat di kawasan pesisir. Penelitian ini dimaksudkan untuk mengetahui kondisi kualitas ekosistem mangrove di Pesisir Kabupaten Kepulauan Natuna melalui analisis sebaran jenis dan kerapatan mangrove.

\section{BAHAN DAN METODE}

Penelitian ini berlokasi di Pesisir Kabupaten Kepulauan Natuna yang meliputi Kecamatan Bunguran Selatan, Kecamatan Bunguran Barat, Kecamatan Bunguran Utara, Kecamatan Binguran Timur Laut, Kecamatan Bunguran Timur, Dan Kecamatan Pulau Tiga. Pengambilan data berlangsung pada Bulan Agustus-September 2015.

Pengumpulan data vegetasi mangrove menggunakan metode Transect Line Plots. Data yang dikumpulkan meliputi jumlah pohon mangrove, jenis vegetasi mangrove, dan DBH (diameter of the trunk at breast height).
Pengolahan data-data mangrove tersebut akan mengahsilkan informasi tentang kerapatan jenis (Di), frekuensi Jenis (Fi), penutupan jenis (Ci), dan indeks nilai penting (INP).

\section{Frekuensi Jenis}

$$
F_{1}=\frac{P_{1}}{\sum P}
$$

$\mathrm{F} 1=$ Frekuensi jenis $\mathrm{i}$,

$\mathrm{Pi}=$ Jumlah petak contoh/plot dimana ditemukan jenis ke-i, dan

$\mathrm{P}=$ Jumlah total petak contoh/plot yang diamati

Frekuensi relatif jenis (Rfi)

$$
R F_{i}=\frac{F_{i}}{\sum F} \times 100
$$

\section{Kerapatan jenis (Di)}

$$
D_{i}=\frac{n_{i}}{A}
$$

dimana;

$\mathrm{Di}=$ Kerapatan jenis ke- $\mathrm{i}$

$\mathrm{ni}=$ Jumlah total tegakan (pohon) dari jenis $\mathrm{i}$

$\mathrm{A}=$ Luas area pengambilan contoh (luas petakcontoh/plot)

Kerapatan relatif dari jenis ke-i

$$
R D_{i}=\frac{n_{i}}{\sum n} \times 100
$$

RDi = Perbandingan antara jumlah tegakan (pohon) jenis ke-i (ni) terhadap total tegakan seluruh jenis $\left(\sum n\right)$

\section{Penutupan Jenis}

$$
C_{i}=\frac{\sum B A}{A}
$$

$\mathrm{BA}=\prod \mathrm{DBH}^{2} / 4\left(\right.$ dalam $\left.\mathrm{cm}^{2}\right), \Pi=3,1416$ suatu konstanta untuk nilai tersebut

$\mathrm{DBH}=$ dimeter batang pohon dari jenis $\mathrm{i}$,

$\mathrm{A}=$ luas total area pengambilan contoh (luas total petak contoh)/plot).

Penutupan relatif jenis $(\mathrm{RCi})$

$$
R C_{i}=\frac{C_{i}}{\sum C} \times 100
$$


Selanjutnya ditentukan indek nilai penting (INP)

$$
\mathrm{INP}=\mathrm{RDi}+\mathrm{RFi}+\mathrm{RCi}
$$

Nilai penting suatu jenis berkisar antara 0-300. Nilai penting ini memberikan suatu gambaran peranan suatu jenis tumbuhan Tabel 1. Kriteria kualitas mangrove

\begin{tabular}{|c|c|c|c|}
\hline \multicolumn{2}{|c|}{ Kriteria } & Penutupan (\%) & Kerapatan (Pohon/Ha) \\
\hline \multirow{2}{*}{ Baik } & Sangat Padat & $\geq 75$ & $\geq 1500$ \\
\cline { 2 - 4 } & Padat & $\geq 50-<75$ & $\geq 1000-<1500$ \\
\hline Rusak & Jarang & $<50$ & $<1000$ \\
\hline
\end{tabular}

Sumber: (Men LH 2004)

\section{HASIL DAN PEMBAHASAN}

\section{Tipologi Ekosistem Mangrove}

Mangrove menggambarkan spesies pohon-pohon khas atau semak-semak yang hidup di daerah intertidal dengan habitat yang tergenang dan bersalinitas (Hogarth 2015 Feller and Sitnik 2002; Nagelkerken et al. 2008). Daerah intertidal merupakan daerah pesisir yang memiliki fluaktuasi faktor lingkungan yang tinggi, seperti suhu, sedimen dan pasang surut (Nagelkerken et al. 2008). Mangrove mampu beradaptasi terhadap kondisi lingkungan tersebut, sekalipun demikian mangrove tidak hanya tumbuh di daerah intertidal saja. Mangrove tumbuh juga di sisi sungai hingga muara sungai (Feller and Sitnik 2002). Sebaran mangrove juga dipengaruhi suhu, sehingga mangrove hanya ditemukan di daerah tropis dan subtropics (Hoste 2011). Di kawasan pesisir Natuna, sebagian besar ekosistem mangrove memiliki tipologi Riverine Mangrove. Menurut (Woodroffe 1992) dan (Hoff et al. 2014) riverine mangrove tumbuh di sepanjang daerah aliran sungai. Tipologi mangrove yang demikian dicirikan tumbuh di sepanjang sungai dan anak sungai di mana air umumnya payau (Melana et al. 2000; Feller and Sitnik 2002). Mangrove sungai berada dekat saluran sungai dan secara berkala dibanjiri oleh air tawar dan payau yang kaya nutrisi (Hoff et al. 2014).

Tipologi mangrove tepi juga terdapat ditemukan di Pesisir Bunguran Utara. Mangrove tepi ditemukan tumbuh langsung menghadap ke arah laut tumbuh dengan kerapatan pohon yang rendah. Pada tipologi mangrove yang dominan dalam komunitas mangrove. Kualitas mangrove dianalisis menngunakan Keputusan Menteri Negara Lingkungan Hidup Nomor: 201 Tahun 2004, kriteria baku kerusakan mangrove ditetapkan berdasarkan kerapatan mangrove (Tabel 1).

mangrove ini selain jenis mangrove sejati juga tumbuh jenis tanaman asosiasi, seperti Hibiscus, Casuariana, dan Pandanus Karakteristik substrat pasir yang miskin nutrien, suplai air tawar yang terbatas, dan gelombang yang tinggi terutama pada musim utara menjadikan mangrove di kawasan yang langsung menghadap ke arah laut kurang berkembang. Menurut Hoff et al. 2014 mangrove tumbuh kurang baik di daerah dengan hidrologi terbatas, sehingga kondisi penguapan tinggi, salinitas tinggi, suhu rendah, atau status nutrisi rendah.

\section{Sebaran Jenis Mangrove}

Mangrove tersebar di semua kecamatan yang menjadi lokasi penelitian (Tabel 2). Ekosistem mangrove terluas terdapat di Kecamatan Bunguran Utara yaitu seluas 1.222,56 Ha. Pertumbuhan mangrove yang baik di lokasi ini didukung oleh keberadaan teluk yang menjadi muara banyak sungai. Hal ini mendukung ketersediaan nutien yang cukup dan substrat yang ideal untuk tumbuh kembangnya mangrove. Kecamatan Bunguran Timur Laut memiliki luasan ekosistem mangrove terkecil di kabupaten ini yaitu seluas 43,25 Ha. Karakteristik wilayah Bunguran Timur Laut yang menghadap laut terbuka maka ketersediaan nutrien di habitat mangrove sangat rendah, sehingga mangrove kurang mampu tumbuh dengan baik di wilayah ini. Mangrove hanya tumbuh tipis di tepian sungai dekat muara.

Tumbuhan penyusunan mangrove memiliki karakteristik pohon yang berbedabeda, baik dari ukuran, bentuk akar, batang dan 
daun. Perbedaan tersebut berhubungan dengan adaptasi yang dilakukan terhadap kondisi habitat yang bersalinitas dan bersifat anaerob (Muarif et al. 2016). Jenis-jenis mangrove yang tumbuh di kawasan pesisir Kepulauan Natuna antara lain Aegiceras floridium, Bruguiera gymnorhiza, Ceriops tagal, Casuarina equisetifolia, Excoecaria agalocha, Tabel 2. Sebaran Jenis mangrove di pesisir Kabupaten Kepulauan Natuna

\begin{tabular}{|c|c|c|}
\hline Lokasi & $\begin{array}{l}\text { Luas } \\
(\mathrm{Ha})\end{array}$ & Jenis Mangrove \\
\hline $\begin{array}{l}\text { Kecamatan } \\
\text { Bunguran } \\
\text { Utara }\end{array}$ & 53,19 & $\begin{array}{l}\text { Bruguiera gymnorhiza, Ceriops tagal, Casuarina equisetifolia, } \\
\text { Hibiscus tiliaceus, Lumnitzera littorea, Nypa fructicans, Pandanus } \\
\text { tectorius, Rhizophora apiculata, Rhizophora mucronata, } \\
\text { Sonneratia alba, Xylocarpus granatum }\end{array}$ \\
\hline $\begin{array}{l}\text { Kecamatan } \\
\text { Bunguran } \\
\text { Barat }\end{array}$ & $1.222,56$ & $\begin{array}{l}\text { Bruguiera gymnorhiza, Ceriops tagal, Nypa fructicans, Rhizophora } \\
\text { apiculata, Rhizophora mucronata, Sonneratia alba, Xylocarpus } \\
\text { granatum }\end{array}$ \\
\hline $\begin{array}{l}\text { Kecamatan } \\
\text { Bunguran } \\
\text { Selatan }\end{array}$ & 379,97 & $\begin{array}{l}\text { Bruguiera gymnorhiza, Ceriops tagal, Nypa fructicans, Rhizophora } \\
\text { apiculata, Rhizophora mucronata, Sonneratia alba, Xylocarpus } \\
\text { granatum }\end{array}$ \\
\hline $\begin{array}{l}\text { Kecamatan } \\
\text { Bunguran } \\
\text { Timur }\end{array}$ & 713,75 & $\begin{array}{l}\text { Bruguiera gymnorhiza, Rhizophora apiculata, Rhizophora } \\
\text { mucronata, Sonneratia alba, Xylocarpus granatum }\end{array}$ \\
\hline $\begin{array}{l}\text { Kecamatan } \\
\text { Bunguran } \\
\text { Timur Laut }\end{array}$ & 43,25 & $\begin{array}{l}\text { Bruguiera gymnorhiza, Rhizophora apiculata, Rhizophora } \\
\text { mucronata, Sonneratia alba }\end{array}$ \\
\hline $\begin{array}{l}\text { Kecamatan } \\
\text { Pulau Tiga }\end{array}$ & 120,96 & $\begin{array}{l}\text { Aegiceras floridium, Bruguiera gymnorhiza, Ceriops tagal, } \\
\text { Excoecaria agalocha, Heritiera littoralis, Phemphis acidula, } \\
\text { Rhizophora apiculata, Rhizophora mucronata, Rhizophora } \\
\text { lamarchii, Sonneratia alba, Xylocarpus granatum }\end{array}$ \\
\hline
\end{tabular}

Jenis mangrove yang dominan tumbuh di kawasan pesisir Natuna adalah genus Rhizophora, seperti Rhizophora mucronata, Rhizophora stylosa, dan Rhizophora apiculata (Tabel 3). Jenis mangrove ini memiliki akar tunjang sehingga mampu beradaptasi dengan baik pada lingkungan yang senantiasa terendam air. Jenis-jenis Rhizophora tersebut tumbuh di bagian depan sepanjang tepian sungai. Pertumbuhan Rhizophora yang baik terdapat dizona bagian depan disebabkan sistem perakarannya yang mampu beradaptasi pada daerah tergenang dan mampu menahan ombak, serta kemampuan adaptasi pada salinitas yang lebih tinggi. Menurut (Giesen et al. 2007) Rhizophora tumbuh optimal pada salinitas $1,2 \%$.

Karakteristik komunitas mangrove di DAS Sungai Binjai Kecamatan Bunguran Barat memiliki perbedaan pada beberapa
Heritiera littoralis, Hibiscus tiliaceus , Lumnitzera littorea, Nypa fructicans, Pandanus tectorius, Phemphis acidula, Rhizophora apiculata, Rhizophora mucronata, Rhizophora lamarchii, Rhizophora stylosa, Sonneratia alba, dan Xylocarpus granatum (Tabel 2). 
mangrove di atas 1.500 individu/Ha, sehingga ekosistem mangrove di wilayah ini tergolong memiliki kualitas yang baik dengan tingkat kerapatan sangat padat. Kualitas ekosistem mangrove yang baik dengan tingkat kerapatan sangat padat juga terdapat sepanjang tepian sungai yang berada di perbatasan Kecamatan Bunguran Timur dan Kecamatan Bunguran Selatan dengan nilai kerapatan 1.625 individu/Ha. Sebaran kualitas mangrove di daerah lainnya tergolong baik dengan tingkat kerapatan padat.

Pada daerah yang memiliki kerapatan yang sangat tinggi, mangrove tumbuh dengan baik didukung oleh keberadaan sungai yang besar sehingga mampu menyediakan nutrien yang cukup untuk pertumbuhan mangrove. Menurut Hoff et al. (2014) nutrisi menjadi faktor penting yang mengendalikan pertumbuhan mangrove. Keberadaan sungai besar juga menyumbang air tawar yang tinggi sehingga salinitas tergolong sedang. Rhizophora merupakan jenis mangrove yang mampu tumbuh pada salinitas tidak terlalu tinggi, sehingga jenis ini mendominasi hampir di seluruh stasiun penelitian.

Kualitas ekosistem mangrove di seluruh lokasi penelitian tergolong baik. Kondisi ini menjadikan peran ekosistem mangrove tinggi dalam mendukung produktivitas sumberdaya pesisir dan lautan. Untuk menjaga keberlanjutan produktivitas sumberdaya pesisir dan lautan di kabupaten ini, maka kebijakan konservasi untuk menjaga dan meningkatkan kualitas ekosistem mangrove sangat penting untuk diterapkan.

Tabel 3. Kerapatan pohon, vegetasi dominan dan kualitas ekosistem mangrove

\begin{tabular}{|c|c|c|c|c|}
\hline \multirow{2}{*}{ Lokasi } & \multicolumn{2}{|c|}{ Kerapatan (idv/Ha) } & \multirow{2}{*}{ Jenis dominan } & \multirow{2}{*}{$\begin{array}{l}\text { Kualitas } \\
\text { ekosistem } \\
\text { mangrove }\end{array}$} \\
\hline & Kisaran & Rataan & & \\
\hline $\begin{array}{l}\text { Kecamatan Bunguran } \\
\text { Utara }\end{array}$ & $\begin{array}{l}1.267- \\
1.340\end{array}$ & 1.280 & Rhizophora mucronata & Baik (padat) \\
\hline $\begin{array}{l}\text { Kecamatan Bunguran } \\
\text { Barat }\end{array}$ & $\begin{array}{l}1.000- \\
2.133\end{array}$ & 1.833 & $\begin{array}{l}\text { Rhizophora apiculata, } \\
\text { Rhizophora mucronata, } \\
\text { Rhizophora stylosa, Nypa } \\
\text { fructicans, Xylocarpus } \\
\text { granatum }\end{array}$ & $\begin{array}{l}\text { Baik (padat)- } \\
\text { Baik (sangat } \\
\text { padat) }\end{array}$ \\
\hline $\begin{array}{l}\text { Kecamatan Bunguran } \\
\text { Selatan }\end{array}$ & $\begin{array}{l}1.000- \\
1.467\end{array}$ & 1.567 & Rhizophora mucronata & Baik (padat) \\
\hline $\begin{array}{l}\text { Kecamatan Bunguran } \\
\text { Timur }\end{array}$ & $\begin{array}{l}1.100- \\
1.625\end{array}$ & 1.363 & $\begin{array}{l}\text { Rhizophora apiculata, } \\
\text { Rhizophora mucronata }\end{array}$ & $\begin{array}{l}\text { Baik (padat)- } \\
\text { Baik (sangat } \\
\text { padat) }\end{array}$ \\
\hline $\begin{array}{l}\text { Kecamatan Bunguran } \\
\text { Timur Laut }\end{array}$ & 1.300 & 1.300 & Rhizophora mucronata & Baik (padat) \\
\hline Kecamatan Pulau Tiga & 1.100 & 1.100 & Bruguiera gymnorrhiza & Baik (padat) \\
\hline
\end{tabular}

\section{KESIMPULAN}

Kondisi ekosistem mangrove di Pesisir Kepulauan Natuna tergolong baik. Kerapatan mangrove tergolong padat sampai sangat padat dengan nilai kerapatan 1.000-2.933 idv/Ha. Kecamatan Bunguran Barat memliki areal mangrove terluas dengan rataan kerapatan pohon yang tertinggi. Ekosistem mangrove rata-rata diominansi oleh Genus Rhizophora antara lain jenis Rhizophora mucronata, Rhizophora stylosa, dan Rhizophora apiculata.

\section{UCAPAN TERIMAKASIH}

Terimakasih diucapkan kepada PT. Roda Bahari yang telah memfasilitasi peneliti dalam melakukan survei, serta kepada Resi dan Rahmat yang telah membantu selama survei.

\section{DAFTAR PUSTAKA}

BPS Kabupaten Natuna. 2014. Natuna dalam angka 2014. Ranai: Badan Pusat Statistik Kabupaten Natuna. 
Feller, I. C. and Sitnik, M. 2002. Mangrove ecology: a manual for a field course. Washington: Smithsonian Institution.

Giesen, W., Wulffraat, S., Zieren, M. and Scholten, L. 2007. Mangrove guidebook for Shoutheast Asia. Bangkok: FAO and Wetlands International.

Hoff, R., Michel, J., Philippe, H., Proffitt, E. C., Delgado, P., Shigenaka, G., Yender, R. and Mearns, A. J. 2014. Oil Spills in Mangroves. Edited by R. Hoff and J. Michel. Washington: U.S. Department of Commerce.

Hogarth, P. J. 2015. The Biology of Mangroves and Seagrasses. Third Edit. New York: Oxford University Press.

Hoste, P. 2011. Ecophysiology of mangrove in Australia: hydraulic functioning. Gent: Universiteit Gent.

MacDonald, J. A. 2008. Variation among mangrove forest as fish habitat: the role of prop-root epibiont, edge effect and behavior in neotropical mangrove. New Brunswick: The State University of New Jersey.

Melana, D. M., Yao, C. E., Edwards, R., Melana, E. E. and Gonzales, H. I. 2000. Mangrove Management Handbook. Cebu: Department of Environment and Natural Resources, Manila, Philippines through the Coastal Resource Management Project.

Men LH. 2004. Keputusan Menteri Negara Lingkungan Hidup NOMOR: 201 TAHUN 2004 Tentang Kriteria Baku dan Pedoman Penentuan Kerusakan Mangrove. Jakarta: Men LH, p. 8.
Muarif. 2016a. Pengembangan Indeks Kepekaan Ekologi (IKE) Ekosistem Mangrove Terhadap Tumpahan Minyak. Sekolah Pascasarjana Institut Pertanian Bogor.

Muarif. 2016b. 'Potensi, peluang dan tantangan pengelolaan dan pemanfaatan sumberdaya kelautan dalam rangka pembangunan nasional berbasis pengembangan ekonomi kelautan', Seminar Nasional Wawasan Nusantara, 28 Desembe, p. 17.

Muarif, Damar, A., Hariyadi, S., Boer, M. and Soetrisno, D. 2016. Tingkat kepekaan mangrove Indonesia terhadap tumpahan minyak, Jurnal Manusia dan Lingkungan, 23(3), pp. 374-380.

Muarif, Damar, A., Hariyadi, S., Sutrisno, D. and Boer, M. 2016. A Framework for Screening of Variables of Ecological Sensitivity Index ( ESI ) of Mangrove Ecosystems to Oil Spills', International Journal of Sciences: Basic and Applied Research (IJSBAR), 27(1), pp. 142-153.

Nagelkerken, I., Blaber, S. J. M., Bouillon, S., Green, P., Haywood, M., Kirton, L. G., Meynecke, J., Pawlik, J., Penrose, H. M., Sasekumar, A. and Somerfield, P. J. 2008. The habitat function of mangroves for terrestrial and marine fauna: A review, Aquatic Botany, 89, pp. 155185. doi: 10.1016/j.aquabot.2007.12.007.

Woodroffe, C. 1992. Mangrove Sediments and Geomorphology, in Robertson, A. I. and Alongi, D. M. (eds) Mangrove Tropical Ecosystems. Queensland: American Geophysical Union, p. 280. 